\title{
Posiciones estratégicas y fuerza obrera: Apuntes en torno a un ciclo huelguístico de los estibadores del salitre (Chile 1916-1923)
}

\author{
Strategic positions and workers' strength: Notes around a strikes cycle in the \\ saltpeter docks (Chile 1916-1923)
}

\author{
Camilo Santibáñez Rebolledo*
}

\begin{abstract}
Resumen: Este artículo busca interrogar la aplicabilidad de la propuesta analítica de John Womack Jr. sobre la fuerza obrera, a partir del examen de un ciclo huelguístico (1916-1923) protagonizado por los trabajadores portuarios en uno de los nervios más sensibles y estratégicos de la economía chilena de la época: los muelles embarcadores de salitre. Según sostiene la hipótesis, y prueba el acucioso estudio de una veintena de huelgas, laborar en el sitio más vulnerable del circuito exportador, no les habría significado un garante de fuerza a los referidos trabajadores en dichos conflictos laborales. Básicamente porque, tratándose de hombres prescindibles, en la mayoría de los casos fueron desplazados de la "posición estratégica" en la que, de acuerdo a la teoría, se hallaban.
\end{abstract}

Palabras clave: Posición estratégica, conflictos laborales, estibadores, historia de Chile.

\begin{abstract}
This paper seeks to examine the applicability of John Womack Jr's framework on workers' strength. To do so, the paper examines the 1916-1923 strikes led by dock workers in one of the most sensitive and strategic sectors of the Chilean economy at that time: the saltpeter docks. Based on the thorough study of over twenty strikes, this paper aims to show that working in the most vulnerable place of the export circuit did not necessarily imply that these workers had the strength suggested by Womack Jr's framework. The data show that these workers were dispensable, so in most cases they were displaced from the "strategic position" where they were theoretically located.
\end{abstract}

Keywords: Strategic position, labor conflicts, dock workers, history of Chile.

Recibido: 20 junio 2016

Aceptado: 27 agosto 2016

${ }^{*}$ Chileno. Tesista y Becario CONICYT-PCHA/Magíster Nacional/2013-221320063, en el Programa de Magíster en Historia de la Universidad de Santiago de Chile. Correo electrónico: sntibaez@gmail.com 


\section{Introducción}

En el XIV International Economics History Congress, celebrado en 2006, John Womack Jr. presentó un acucioso ensayo, intitulado Working Power over Production: Labor History, Industrial Work, Economics, Sociology, and Strategic Position. Un año más tarde, con algunos arreglos, el trabajo fue publicado en español por el Fondo de Cultura Económica en conjunto con el Fideicomiso Historia de las Américas de El Colegio de México, y difundido en Latinoamérica bajo el título Posición estratégica y fuerza obrera. Hacia una nueva historia de los movimientos obreros. Para el objetivo planteado en el subtítulo, el escrito, de carácter eminentemente bibliográfico, formulaba una propuesta analítica para estudiar el "poder técnicamente determinado" de los trabajadores, conferido por las posiciones industrialmente estratégicas que tales trabajadores ocupaban (o no ocupaban) en la producción. Esto, con el propósito de examinar "si los obreros en cuestión percibían o no sus oportunidades y si hacían o no todo lo que podían con ellas", e igualmente establecer las limitantes que explicarían "por qué [determinados trabajadores] hacían cuanto hacían". "En el caso chileno, sin embargo, con la excepción de los escritos de Hernán Venegas sobre "La posición estratégica de los trabajadores del carbón" recepción de esta obra no parece haber generado mayor eco entre los historiadores laborales. ${ }^{3}$

Con el propósito de revisar la relación entre Posición estratégica y fuerza obrera en otro destacamento de la fuerza de trabajo chilena -secundando el caso carbonífero-, este artículo busca interrogar la aplicabilidad de la propuesta analítica de John Womack Jr. a partir del examen de un álgido ciclo huelguístico (1916-1923) protagonizado por los trabajadores portuarios en otro de los nervios sensibles e industrialmente estratégicos de la economía nacional: los muelles

\footnotetext{
${ }^{1}$ John Womack Jr., "Working Power over Production: Labor History, Industrial Work, Economics, Sociology, and Strategic Position", XIV International Economic History Congress, Panel 56: The Economics of Latin American Labor, Helsinki, 2006; Posición estratégica y fuerza obrera. Hacia una nueva historia de los movimientos obreros, México, FCE-Fideicomiso Historia de las Américas, Colegio de México, 2007. Los entrecomillados del párrafo corresponden a la obra en español, página 51. Todas las referencias posteriores a este autor corresponden al mismo volumen.

${ }^{2}$ Hernán Venegas, "De imprescindibles a marginados. Las movilizaciones de los trabajadores del carbón en Chile a mediados del siglo XX", Tiempo Histórico, N³, Santiago, 2011, 105-126; "Anticomunismo y control social en Chile, la experiencia de los trabajadores del carbón en Lota y Coronel, a mediados del siglo XX", Revista de Historia Social y de las Mentalidades, N16, Vol. 2, 2012, 79-106; "La posición estratégica de los trabajadores del carbón en Chile. De su fortaleza a la crisis, 1920-1960”, Anos 90, N¹9, Vol. 35, Porto Alegre, 2012, 445-474.

${ }^{3}$ Una segunda excepción, más reciente y enfocada no en los trabajadores, sino en el empresariado, es un artículo de Sergio González Miranda sobre el modo en que, a partir de la incorporación y el manejo de la idea de crisis de las exportaciones del salitre, las firmas productoras de este mineral se habrían organizado en "combinaciones" para controlar la producción y comercialización del nitrato, consiguiendo situarse en una "posición estratégica", y por tanto política, frente al estado chileno, desde 1884. Categoría, la entrecomillada, que González Miranda tomó también del texto en referencia. Ver: Sergio González Miranda, “Normalización' de la crisis y posición estratégica empresarial durante la expansión de la economía del salitre", Polis, Revista Latinoamericana, 40:14, Santiago, 2015, 397-419. Sobre la escasa utilización historiográfica de los planteamientos de Womack Jr., el contraste es bastante perceptible respecto del más temprano y mayor uso que los sociólogos le han dado en sus investigaciones recientes sobre el sindicalismo chileno actual. La primera de dichas investigaciones parece haber sido una reseña crítica sobre el libro -también apuntada en la bibliografía-, realizada por Santiago Aguiar los primeros días de 2009, centrada en el concepto de "posición estratégica" y aplicada a un estudio en curso sobre la industria forestal chilena: Santiago Aguiar, "El concepto de 'posición estratégica'. Reseña de un libro y avances de una investigación”, Cuadernos de Estudios del Trabajo, $\mathrm{N}^{\circ} 12$, Santiago, 2009.
} 
embarcadores de salitre. ${ }^{4}$ La hipótesis que atraviesa el ejercicio propone que, en efecto, los obreros portuarios nortinos laboraban en uno de los sitios más vulnerables de una industria evidentemente estratégica; pero que ello no significaba que dichos trabajadores pudiesen convertir las paralizaciones del flujo mercantil en garantía de fuerza obrera, ni otorgarse una buena posición negociadora en los conflictos laborales. Básicamente porque, si bien podían impedir de modo momentáneo los embarques, dichas paralizaciones de faenas eran efectuadas por hombres sustituibles; y por tanto, estos eran incapaces de sostenerlas de modo lo suficientemente determinante como para doblegar a su contraparte patronal. Cuestión que, en el balance, y dada la propensión de estos trabajadores a la huelga, habría afectado de manera desfavorable a los mismos obreros.

Metodológicamente, por tanto, el grueso del escrito se ha destinado a documentar los resultados de los conflictos laborales que detonaron las principales paralizaciones en los puertos salitreros durante el período señalado; reconstrucción que debió acudir a una importante cantidad de prensa obrera y no obrera, publicaciones patronales e informes gubernamentales, que, por su parcialidad y extensión como fuentes, han sido trenzadas complementaria y narrativamente, limitando las referencias a pie de página, únicamente en los casos ineludibles y en las citas textuales, y priorizando, además, los documentos más relevantes. ${ }^{5} \mathrm{Su}$ tratamiento ha consistido en denotar el rol que la capacidad de paralización obrera jugó en tales resultados, para posteriormente contrastarlo con los presupuestos teóricos sobre el "poder técnicamente determinado" de los estibadores.

Para organizar el ejercicio propuesto, y brevemente prologados por algunas notas teóricas útiles en torno al estudio de las huelgas portuarias, el texto se ha ordenado en tres apartados que, respectivamente, exponen los reveses huelguísticos de los obreros portuarios nortinos en 19161917; sus posteriores triunfos, obtenidos también por paralizaciones en 1919-1920; y finalmente, los nuevos fracasos de los mismos trabajadores en 1921 y 1923. Tras estos tres apartados, se ensayan algunas conclusiones, poniendo énfasis en ciertos aspectos descuidados por Womack Jr. que, conjuntamente con su propuesta, podrían contribuir al estudio histórico de otros flancos del movimiento obrero chileno.

Tres últimas cuestiones deben advertirse de modo previo, en torno a los límites de este escrito. La primera es que, del breve pero agitado período que este artículo considera -cuya justificación se basa en que conforma un ciclo de conflictos en torno al control de la contratación, sólo han sido revisadas las huelgas más importantes, quedando fuera de consideración numerosos conflictos portuarios de menor relevancia para el propósito esbozado. La segunda es que, con el objeto de estudiar las posiciones estratégicas dadas únicamente por el trabajo, otros aspectos han sido omitidos en el estudio de tales paralizaciones; particularmente las diferentes

\footnotetext{
${ }^{4}$ Como han señalado estudios recientes, el salitre representaba alrededor del $70 \%$ de las exportaciones nacionales hacia 1916 y prácticamente la mitad de la recaudación tributaria nacional. Mario Matus González, "Fulgor y muerte del jornal salitrero en Chile, 1899-1930", Sergio González Miranda, La sociedad del salitre. Protagonistas, migraciones, cultura urbana y espacios públicos, 1870-1940, RIL, Santiago, 2013, 508-509.

${ }^{5}$ Originalmente fueron ocupadas alrededor de setecientas notas al pie para documentar las huelgas en cuestión, incorporando, la mayoría de ellas, más de una referencia. La totalidad de estas fuentes pueden consultarse en: Camilo Santibáñez Rebolledo, "Huelgas y lockouts portuarios por la redondilla. Los conflictos por el control de la contratación en los muelles chilenos (1916-1923)", Tesis inédita para optar al grado de Magíster en Historia, mención Historia de Chile, por la Universidad Santiago de Chile, Santiago, 2015.
} 
subjetividades que explican sus estallidos. La tercera, de tipo terminológico, es que, por "estibadores del salitre", el título de este artículo busca aludir de manera genérica a los embarcadores portuarios involucrados en la carga de este mineral -esto es: cargadores, lancheros, jornaleros y estibadores-, y no solo a la ocupación diferenciada en las faenas de carga marítima que dicho término denominaba durante aquellos años.

\section{Notas sobre la "posición estratégica" y algunas consideraciones para el estudio de las huelgas portuarias}

Resumiendo su peregrinar por la historiografía laboral, John Womack Jr. planteaba el problema de las "posiciones estratégicas" del siguiente modo:

La mayoría de los historiadores de organizaciones obreras hablaban acerca de obreros "clave" o en "posición estratégica" y de su "estrategia" en la economía en general o en ciertas industrias o plantas particulares. (...) Lo más complicado era que a veces argumentaban como si una misma posición volviera estratégico al obrero y otras veces lo contrario. Además no eran claros en cuanto a qué hacía estratégicos una posición o a determinados obreros. Algunos argumentaban que era la importancia de toda una industria o un sector en la economía en general, sin vincular esta idea con posiciones particulares. Otros hablaban de las consecuencias extraordinarias de una posición en "el proceso de producción" o "el proceso laboral", por cierta conexión tecnológica que a menudo esbozaban. Otros más atribuían lo estratégico a las "habilidades" de los obreros, sus capacidades tecnológicas, a menudo dejando de lado las excepciones, como los estibadores. Algunos defendían ambos criterios técnicos: el trabajo "estratégico" debía ser importante para la producción y también calificado; se trataba de ciertas funciones o tareas que sólo podían realizar obreros con una preparación especial. ¿Qué ocurría entonces con los estibadores o los conductores del transporte de carga? ${ }^{6}$

No obstante, como bien sostiene el propio Womack Jr., la strategic position como categoría de análisis para entender históricamente las relaciones laborales, que había sido propuesta originalmente por John T. Dunlop en la década de 1940, buscaba referir precisamente aquellas posiciones "que le [permitían] a algunos obreros detener la producción de muchos otros, ya sea dentro de una compañía o en toda una economía, como los torneros o", nótese, "los estibadores". 7

Según parece, en este mismo sentido es que Poulantzas empleó luego el término bottleneck strikes (1974), y también algunos sociólogos del trabajo, como Durand y Dubois, al hablar de grève-thrombose y grève-bouchon (1975). Es decir, metáforas para referir lo que un historiador alemán, Thomas Welskopp, categorizaría más tarde como Störmacht (1994): un poder técnico de obstrucción que posicionaba estratégicamente a determinados trabajadores, conferido

\footnotetext{
${ }^{6}$ Womack Jr., op. cit., 24-25. En la cita, ha sido incorporado el destacado de la palabra "estibadores".

${ }^{7}$ Ibid., 50.
} 
precisamente por la posibilidad que los mismos tenían para interrumpir la producción de toda una fábrica o industria. ${ }^{8}$

En lo que a la estiba y desestiba de barcos refiere, Eric J. Hobsbawm había planteado, en 1964, que los obreros portuarios disponían de un "poder disruptivo" para esgrimir en los conflictos laborales, entendido como la capacidad de interrumpir súbitamente el tráfico comercial, infligiendo graves pérdidas financieras y perturbando a un más amplio sector económico involucrado, mediante el impedimento o el retardo del transporte de mercancías o materias primas. De hecho, el idioma original del recientemente fallecido historiador, permite que la aseveración "Dock labour is powerful because its capacity to strike is powerful", conserve en la palabra strike el doble significado de huelga y de la dureza del golpe provocado. ${ }^{9}$

En el caso de los obreros portuarios chilenos, Julio Pinto Vallejos dio cuenta de esta capacidad al estudiar la huelga general del invierno de 1890 -la primera de esta magnitud en la historia del país- y el rol central que el Gremio de Jornaleros y Lancheros iquiqueño había tenido en su gestación y conducción; contrariando de manera documentada la adjudicación de dicho rol al proletariado minero por parte de algunos historiadores precursores. ${ }^{10}$ Para explicar tamaña capacidad, Julio Pinto argumentó que estos obreros, situados en "el nudo más estratégico" de la economía tarapaqueña, contaban con una larga tradición organizativa gremial (gubernamentalmente tutelada), producto de la cual habían adquirido conciencia no sólo de su importancia para el funcionamiento de la economía, sino también de las ventajas que la acción colectiva podía reportarles al hallarse situados en plena "válvula" del comercio regional. "No era difícil que este instrumento", dijo Pinto refiriéndose al Gremio en cuestión, "pudiese emplearse en función de la iniciativa de sus propios miembros, desligándolo de la tutela gubernamental"; "Esto ya había sucedido en algunas ocasiones antes de 1890", agregó, "y muy especialmente en una huelga que paralizó por todo un mes el puerto de Iquique en 1887”. "En dicha oportunidad, y pese a la resistencia de las autoridades y el temor empresarial, el éxito había sido total"; razón por la que, según infirió Pinto, los obreros portuarios habrían confiado disponer de "una herramienta ya probada". ${ }^{11}$ En un artículo publicado cuatro años más tarde, en 1994, este historiador ratificaría su argumentación, planteando que: "la posición estratégica en que los situaba tanto su función económica como el monopolio estatal que los favorecía, otorgó a los portuarios una capacidad de negociación única en la región, reforzada seguramente por el ánimo asociativo

\footnotetext{
${ }^{8}$ Ibid., 174, 93, 26.

${ }^{9}$ Eric J. Hobsbawm, "National Unions on the Waterside", E. J. Hobsbawm, Labouring Men. Studies in the History of Labour, Londres, Weidenfeld and Nicolson, 1964, 219 y 204.

${ }^{10}$ La versión de este artículo que ha sido consultada es la que integra el volumen Trabajos y rebeldías en la pampa salitrera del mismo autor, citado en la bibliografía. La versión original en: Julio Pinto Vallejos, "La transición laboral en el norte salitrero: La provincia de Tarapacá y los orígenes del proletariado en Chile 1870-1890", Historia, 25, Santiago, 1990, 207-228. Una revisión del tratamiento que los trabajadores portuarios han recibido en la historiografía obrera, puede consultarse en: Santibáñez Rebolledo, op. cit., 8-28.

${ }^{11}$ Ibid., 52-53. 
inculcado por el gremio oficial". ${ }^{12}$ Como es sabido, sin embargo, la huelga de 1890 culminó en un completo y duro fracaso, que significó inclusive la derogación de los gremios aludidos. ${ }^{13}$

No obstante, la representación que Julio Pinto hizo de los muelles tarapaqueños como "válvula", grafica de manera impecable lo que Frederick Cooper, un especialista de la historiografía portuaria, planteó una década más tarde como premisa teórica para el estudio de las relaciones laborales en los terminales marítimos: "El trabajo portuario es, en primer lugar, absolutamente crucial para la consecución de los frutos del esfuerzo productivo capitalista, pero al mismo tiempo, la concentración de trabajadores en un espacio reducido, lo hace particularmente vulnerable a la interrupción". ${ }^{14}$ Relación que, junto a referirlos como situados en una "posición estratégica", ponen de manifiesto que, implícita o germinalmente, las conclusiones del historiador chileno contenían un marco teórico para examinar el origen de la "fuerza obrera" que la interrupción del trabajo les brindaba a los estibadores del salitre; pese a no poner dichas categorías en discusión para explicar el fracaso de la misma en 1890.

En este marco, debe apuntarse, laborar en la referida "válvula" no hacía automáticamente "estratégicos" a tales obreros. Aunque el historiador no llega a explicitarlo de este modo, las condiciones tecnológicas y el proceso de trabajo en el que se desarrollaban las faenas de embarque del nitrato, resultaban igualmente fundamentales como factores para explicar la posición estratégica que el trabajo le confería a dichos obreros portuarios; factores sin los cuales la duración y el resultado de una huelga como la de 1887 en Iquique, por ejemplo, resultarían imposibles de explicar. La queja del Comandante del Gremio de Jornaleros con motivo de la referida huelga, aludiendo lo "necesarios e irremplazables" que eran dichos obreros, tiende a corroborar esta impresión, pues su alegato se centraba en cómo las faenas portuarias requerían de "hombres de fuerzas verdaderamente especiales, habituados por una larga práctica a este servicio, [para el que no se disponía de] líneas férreas ni muelles adecuados al objeto". ${ }^{15}$ Lo que cabría esclarecer, por tanto, a efectos de un ejercicio como el propuesto en este escrito y antes de examinar las huelgas en cuestión, son las condiciones tecnológicas en las que se desarrollaban las faenas de embarque del salitre hacia 1916-1923.

En Iquique, por ejemplo, al comienzo de dicho período, los cargadores descargaban y transportaban en sus hombros el nitrato ensacado, traído desde la pampa en los carros del ferrocarril, y lo apilaban en rumas en las bodegas o lo movían en carros manuales a los muelles, donde un empleado de aduana los pesaba para el cobro de los derechos de exportación. Como los calados no eran de la profundidad adecuada para el atraque de los buques, los sacos eran arrojados por "canales" a los lanchones: embarcaciones que eran conducidas a remo por los lancheros hasta el costado de los buques. Finalmente, el carguío de las naves era efectuado por

\footnotetext{
12 Julio Pinto Vallejos, "En el camino de la mancomunal: Organizaciones obreras en la provincia de Tarapacá (18801895)", Julio Pinto Vallejos, Trabajos y rebeldías en la pampa salitrera. El ciclo del salitre y la reconfiguración de las identidades populares (1850-1900), Santiago, Universidad de Santiago de Chile, 1998, 179. Este artículo fue originalmente publicado en el $\mathrm{N}^{\circ} 14$ de Cuadernos de Historia.

13 Sobre la huelga general de 1890 puede consultarse el trabajo de Sergio Grez Toso, De la "regeneración del pueblo" a la huelga general: génesis y evolución histórica del movimiento popular en Chile (1810-1890), Santiago, RIL, 2007, en particular las páginas 717-762. Sobre la destrucción de los gremios portuarios, además de la última referencia, ver el trabajo de Julio Pinto Vallejos citado en la nota al pie anterior, páginas 191-197.

${ }^{14}$ Frederick Cooper, "Dockworkers and labour history", Colin Davies, Dock workers. International Explorations in Comparative Labour History, 1790-1970, Aldershot-Vermont, Ashgate, 2000, 526.

${ }^{15}$ La cita ha sido tomada de Julio Pinto Vallejos, "La transición laboral...", 178-179.
} 
jornaleros marítimos y estibadores contratados por los capitanes de los buques por intermedio de los contratistas. ${ }^{16}$ Aunque en 1902 el gobierno había fijado el peso de estos sacos en 106 kilos como máximo, cabe precisar, el grupo de parlamentarios que visitó las faenas en 1916 halló que estos excedían generalmente los 120, comprobando inclusive sacos que pesaban treinta kilos más de lo permitido. ${ }^{17}$

Respecto de las bodegas de almacenaje, la ley establecía, desde 1901, "que los obreros cargadores en sus faenas de descarga del salitre, sólo podrían remontar de 14 sacos": primero, siete, que arrumados medían alrededor de 1.70 metros, pudiendo los cargadores "tirar el [último] saco desde el hombro" a la cima, para en seguida, y mediante una rampla de tablones colocados para subir caminando por ellos a la parte superior de las rumas ya apiladas, iniciar una nueva ruma con siete sacos más. Sin embargo, un accidente acontecido durante 1918 en el mismo puerto, en el que un bulto aplastó a un obrero tras caerle desde una ruma de veintiún sacos -es decir, más de cien kilos cayendo desde más de cinco metros de altura-, evidencia cómo se realizaban las faenas en dichos recintos y la respectiva fuerza involucrada. ${ }^{18}$

En el resto de la región salitrera, fuera de Iquique, la infraestructura portuaria parece haber sido todavía peor, no presentando mejoras significativas respecto de fines del siglo XIX. En un artículo publicado durante 1917 en la revista de la Liga Marítima de Chile, se celebraba "la menor pérdida de salitre en el embarque desde el muelle en el trayecto a la nave y en el carguío desde la lancha a las bodegas de aquella" que brindaba Mejillones, "por cuanto la calma permanente del mar [impedía] la mojadura y la ruptura de los sacos". ${ }^{19}$ En un artículo posterior, refiriéndose a la construcción del puerto de San Antonio como un costoso error, la misma revista señalaba en contraste:

En esos puertos, donde diariamente se embarcan millares de quintales de salitre, es lógico imaginarse que debieran de haber magníficas obras portuarias que facilitasen la faena. Sin embargo, a lo largo de la playa de Iquique y Antofagasta no hay una sola obra de puerto que responda a esta necesidad nacional. Hoy, lo mismo que hace seis lustros, hay las bodegas de planchas de zinc junto a la playa: allí se reciben los sacos a hombro de los wagones del FF.CC., y sin más propulsor que el potente brazo del "roto" se forman las rumas, las que principian a deshacerse a hombro para depositar los sacos en las lanchas que atracan a la orilla: desde la bodega los pesados lanchones navegan a remo, o bien ayudados por una gran vela latina fabricada con arpillera de sacos vacíos, hasta el costado del vapor, y sólo allí encuentran la ayuda del winche, para luego continuar la estiba "a hombro"...

\footnotetext{
${ }^{16}$ Enrique Oyarzún, Juan Enrique Concha y Julio Philippi, Informe presentado al Supremo Gobierno sobre las huelgas de Iquique en 1916, Santiago de Chile, 1917, 3-4. Otros informes anteriores esbozaban de modo muy semejante las condiciones en las que laboraban los obreros portuarios en estos muelles. Por ejemplo: Adam Scott, Informes sobre el mejoramiento de los puertos de Mejillones, Antofagasta, Iquique y Arica, Sociedad "Imprenta y Litografía Universo", Santiago de Chile, 1909.

${ }^{17}$ Enrique Oyarzún, op. cit., 6.

18 “Juan A. Gonzalez”, El Despertar de los Trabajadores, 8 de agosto de 1918.

19 "Importancia comercial de Mejillones y Caleta Coloso", Liga Marítima de Chile. Revista Mensual Ilustrada, Órgano oficial de la Liga Marítima de Chile, marzo de 1917.
} 
[El Gobierno] no se ha preocupado de formar dársenas para el carguío, abrir canales entre el roquerío, montar grúas e instalar medios de transporte y movilización que faciliten la tarea del jornalero. ${ }^{20}$

Esta descripción, sin embargo, parece basarse en una percepción más bien general, pues en verdad no calza con el retrato de las faenas iquiqueñas antes descritas, donde, por ejemplo, las lanchas no atracaban en la orilla y las tareas de los jornaleros sí habían sido facilitadas con muelles enrielados y "canales" para arrojar los sacos a dichas embarcaciones. Que el Intendente manifestara júbilo por el aumento en veinte metros de uno de los muelles iquiqueños, a inicios de 1919, porque el trabajo podría realizarse con una lancha a cada lado del muelle, subsanando "el grave defecto de que antes de su prolongación adolecía: que las lanchas aun á media carga se varaban sentándose de popa" (sic), tiende a probar dichas transformaciones. ${ }^{21}$ También que la prensa obrera rebatiera el intento patronal por prohibir el uso de ganchos, argumentando la rotura de los sacos, señalando que: "la pérdida de salitre no [ocurría] por tales causas, sino que al cargarse las lanchas dejándose caer los sacos desde los muelles". ${ }^{22}$ Lanchas que, no obstante, en puertos como el aludido, seguían siendo conducidas a remo, con más de 200 toneladas de los muelles a las naves, sin los remolques que aparentemente se ocupaban en otros puertos. ${ }^{23}$

En conclusión, el dictamen que el Ingeniero en Jefe y Consultor Técnico de Obras de Puertos del Gobierno había expresado en 1909, insistiendo en la necesidad de "mejorar los puertos [chilenos]", porque "en el verdadero sentido de la palabra, no [existía] ninguno, y se [seguía] trabajando con los métodos rudimentarios más antiguos", resultaba todavía parcialmente aplicable para la costa salitrera una década más tarde. ${ }^{24}$

Retomando el punto trazado, por tanto, cabe elaborar un par de preguntas fundamentales para observar los conflictos laborales de 1916-1923 con los anteojos de Womack Jr., las que, tras el preámbulo anterior, pueden plantearse del siguiente modo: Si en huelgas como la de 1887 habían sido las condiciones tecnológicas de estiba las que habían tornado estratégica la experimentada fuerza física de los obreros portuarios del salitre en las referidas "válvulas" exportadoras regionales, y dichas condiciones habían variado sólo parcialmente hacia 1916-1923 - pues habían sido incorporadas líneas férreas, e incorporados algunos carros, pero buena parte de las faenas seguían teniendo en el centro de su funcionamiento una fuerza de trabajo no menos extraordinaria: ¿Seguían implicando las paralizaciones de los estibadores del salitre un trombo sostenible por parte de los trabajadores para la economía regional? ¿Les seguía brindando fuerza

\footnotetext{
20 "La política portuaria y la Marina Mercante", Liga Marítima de Chile. Revista Mensual Ilustrada, Órgano oficial de la Liga Marítima de Chile, mayo de 1917.

${ }^{21}$ ITAR, Vol. 1149, legajo 171.

22 "Salvagismo", El Sembrador, 11 de agosto de 1923.

23 "Las conquistas económicas acrecientan la miseria proletaria", El Sembrador, 24 de febrero de 1923 y "En las faenas marítimas. Los sistemas brutales de trabajo", El Despertar de los Trabajadores, 7 de abril de 1923.

${ }^{24}$ Adam Scott, op. cit., 42. Se sabe de algunos elementos relativamente adecuados para las faenas de carga aparentemente pertenecientes a los buques-, debido a los accidentes entre los obreros. Por ejemplo: "Debido a que el material que usaban para la descarga era malo", señala una de las crónicas de 1917, "la cadena con que enganchaban los fardos en cuyas puntas llevan unas planchuelas en forma de gancho que llaman cafas, eran demasiado cortas"; lo que provocó que un fardo de sacos se soltara y aplastaran al estibador bajo ellos, provocándole fracturas que lo incapacitaron de modo permanente para el trabajo. "Un accidente a un obrero que no tiene reparo", El Despertar de los Trabajadores, 20 de diciembre de 1918.
} 
obrera dicha posición? ¿La dispusieron en su favor para tensar los resultados de los conflictos laborales?

\section{Las huelgas de 1916-1923 en los puertos salitreros}

\section{Los reveses de 1916-1917}

El estado de la industria salitrera durante 1916-1917, puede sintetizarse según la caracterización que Juan Ricardo Couyoumdjian hizo de este último año, indicando que, durante su curso, la producción había ascendido por primera vez en la historia a tres millones de toneladas; "pero debido a la escasez de barcos y a las huelgas en los puertos salitreros, las exportaciones de ese año estuvieron por debajo de las [también] cifras récord de 1916". ${ }^{25}$ Según los datos oficiales, en 1917 , tales exportaciones sumaban $\$ 614.375,876$ (de 18 peniques) en los puertos tarapaqueños y antofagastinos; lo que representaba el $86 \%$ de las exportaciones nacionales, brillando por contraste con las cargas del puerto de Valparaíso que significaban alrededor del $10 \%{ }^{26}$

Sobre las interrupciones del trabajo que afectaron tales exportaciones durante el primero de aquellos años, las acontecidas en la bahía iquiqueña resultan particularmente convenientes de estudiar. El 27 de abril, tras no ser oídos por la casa embarcadora, pese a cursar advertencias con una semana de anticipación, los lancheros de la casa Buchanan Jones iniciaron la primera de tales paralizaciones, exigiendo la remoción de un capataz con el que habían tenido constantes fricciones. En respaldo de los huelguistas, los cargadores de la misma bodega manifestaron que no trabajarían con otros lancheros, cesando también sus faenas. Tras haber fracasado la firma en imponer sus términos para acordar la reanimación de la estiba, los patrones de todas las bodegas más importantes de Iquique declararon el lockout, el 3 de mayo, secundando a Buchanan y paralizando el tráfico en la bahía. Razón por la cual, pese a que lo intentaron, ninguno de los trabajadores pudo retornar a las faenas. Tras una semana en esta situación, y con buques de guerra enviados por el gobierno apostados en la bahía, los patrones reabrieron las bodegas para aquellos obreros con probada "buena conducta" que quisieran retornar al trabajo; condición que significaba la eliminación de más de cincuenta cargadores. Para el 27 de mayo, a un mes de haber estallado el conflicto, dicho número había descendido a tres: el presidente, vicepresidente y secretario del Sindicato de Cargadores. Tres obreros con veinte años laborando en las faenas portuarias, sin ningún cargo ni queja por parte de los capataces ni los jefes de bodegas, pero "que [habían] desempeñado en distintas ocasiones comisiones que todos los cargadores les [habían] confiado". El día 30 del mismo mes, el gremio que aunaba a estibadores y jornaleros marítimos,

\footnotetext{
25 Juan Ricardo Couyoumdjian, Chile y Gran Bretaña durante la Primera Guerra Mundial y la Postguerra, 19141921, Santiago, Editorial Andrés Bello/Ediciones Universidad Católica de Chile, 1986, 16; también ver las Tablas 11 y 12 en las páginas 274-275 respectivamente.

${ }^{26}$ Desagregado, los puertos nortinos embarcaron ese $86 \%$ del siguiente modo: \$133.296 por Antofagasta; $\$ 124.156$ por Iquique; \$91.494 por Mejillones; $\$ 51.983$ por Caleta Buena; $\$ 48.654$ por Taltal; $\$ 39.736$ por Tocopilla; $\$ 29.700$ por Coloso; \$19.698 por Pisagua y \$12.795 por Junín. El problema social-económico del norte, Informe de los señores Carlos A. Ruiz, Cárlos Fernández Peña, Eujenio Frías y Daniel Martner, nombrados por el Supremo Gobierno para estudiar las condiciones de vida en las provincias de Tarapacá y Antofagasta, Ministerio del Interior, Santiago de Chile, 1919, 17-18. Un mapa de todos los puertos salitreros referidos puede consultarse en el Anexo, al final de este texto.
} 
secundado por otros gremios urbanos y el Partido Obrero Socialista, publicó un manifiesto amenazando con unirse a la huelga si el lockout no era resuelto. Tres días más tarde, habiendo transcurrido treinta y siete de iniciado, un tribunal comisionado por la Intendencia y bajo notoria influencia patronal le puso término al conflicto, manteniendo la expulsión de los dirigentes obreros. La demanda inicial de los lancheros, por cierto, no recibió ninguna atención arbitral. ${ }^{27}$

El evidente fracaso obrero, sin embargo, no amainó los ánimos reivindicativos de los trabajadores durante el segundo semestre. Los propios cargadores, de hecho, mediante su magullado sindicato, amedrentaron a las casas embarcadoras con volver a paralizar las faenas si el peso de los sacos de salitre no era disminuido; exigencia que habían manifestado sin resultados en los albores de la pasada huelga. En esta ocasión, no obstante, el atrevimiento les valió llegar a un acuerdo con las casas hacia los primeros días de octubre, el que consistió, no en reducir el peso de los sacos, sino en pagar un recargo por el exceso en los mismos. Simultáneamente, los lancheros comenzaron a pujar por equiparar el horario de término de la jornada con el resto de los trabajadores de Iquique, considerando la gran cantidad de tiempo que perdían retornando a tierra tras las faenas. El recién fundado Gremio de Jornaleros y Estibadores, en tanto, publicó un manifiesto alrededor del 18 de octubre, exigiendo la sustitución del contratista intermediario por la propia organización, con el propósito de librarse del significativo gravamen sobre el pago por la estiba, y arrogarse de este modo la ganancia íntegra. Rechazada la exigencia, desataron el boicot al intermediario cinco días más tarde, consiguiendo que tanto los lancheros como los cargadores les respaldaran. Sin ningún miramiento por la ley de matrículas, el contratista comenzó a reclutar hombres no habilitados para laborar en las faenas marítimas, y el gobierno local puso a disposición de las casas embarcadoras a los hombres de la marinería y el ejército; medida para la cual la Junta Local Salitrera había enviado un tarifado a la Gobernación Marítima, el mismo día $24 .^{28}$

Según sugieren las fuentes, esto remeció la convicción de alguna fracción de los trabajadores, quienes trataron $-\mathrm{y}$ en parte consiguieron- retornar a las faenas. La solidaridad con los obreros iquiqueños, no obstante, se manifestó prontamente en otras latitudes de la costa salitrera. Desde Pisagua y Caleta Buena, los trabajadores expresaron rápidamente su disposición a paralizar las faenas de modo general; los primeros por sumarse a la eliminación de los intermediarios y los segundos por el inmediato retiro de las tropas de las faenas. ${ }^{29}$

Posiblemente apresurada por estas manifestaciones de soporte, la primera negociación aconteció el 1 de noviembre; siendo acordadas mayoritariamente mejoras tarifarias, pero también que no fuesen ejercidas represalias sobre ningún hombre y que la Gobernación Marítima instaurara y controlara la repartición equitativa y rotativa de turnos entre los obreros, mediante un sistema que fue denominado "redondilla". Esta última proposición, cabe subrayar, significaba

\footnotetext{
${ }^{27}$ Informe preparado por el Secretario de la Asociación Salitrera de Propaganda, Iquique, por pedido del Intendente de la Provincia y del Jefe de la Oficina del Trabajo del Ministerio de Industria y Obras Públicas, 19 de julio de 1916, Archivo Nacional de la Administración (ARNAD), Oficina del Trabajo (OT), Vol. 32, 1917. El legajo tiene como anexos recortes de prensa correspondientes a los periódicos La Provincia y El Tarapacá, correspondientes al 16 de mayo y al 3 de junio de 1916 respectivamente.

${ }^{28}$ Enrique Oyarzún, op. cit., 5-20. El manifiesto aludido en: "Manifiesto del Sindicato de Jornaleros y Estivadores Marítimos", El Despertar de los Trabajadores, 19 de octubre de 1916.

${ }^{29}$ Los comunicados de los obreros de Pisagua y Caleta Buena pueden leerse en: "La huelga. La pantomima de una reunión", El Despertar de los Trabajadores, 29 de octubre de 1916.
} 
una selección arbitraria de aquellos hombres que podían pertenecer a las cuadrillas, y también una mezcla entre los agremiados y los no agremiados; es decir, una combinación entre quienes, hecha la selección de los obreros que conformarían las cuadrillas, habían conseguido retornar a las faenas tras participar en el boicot, y quienes habían hecho de rompehuelgas, obteniendo estos además la condición de matriculados. Como la comisión obrera había sido forzosamente compuesta por trabajadores que la demanda de remover a los intermediarios había dividido, los trabajadores que no habían tomado parte en el boicot, tanto como los que lo habían abandonado, aceptaron los acuerdos sin reparos, a diferencia de los obreros que sí persistieron en el método de presión. En Pisagua, en tanto, durante las mismas horas, estallaba la huelga advertida. También en Caleta Buena y en Junín. ${ }^{30}$

Paradójicamente, con las labores de estiba en buena parte retomadas en Iquique, los cargadores, como los lancheros, mantenían un estado bastante parecido a la huelga hacia la segunda semana de noviembre; siendo buen número de los primeros desligados de las faenas por parte de las casas embarcadoras. En Junín, pese a que la compañía había desalojado a los huelguistas de las casas donde les daba cobijo, y amedrentado al resto con expulsarlos de la ensenada, la paralización no amainó. En Caleta Buena, por otra parte, donde los obreros eran reemplazados por la marinería, los huelguistas desistieron alrededor del 11 de noviembre, abandonando la localidad. En Pisagua en cambio, donde los trabajadores habían retornado al trabajo antes, retomaron la paralización por desacuerdos con los patrones en torno a las tarifas, y volvieron a bajarla al obtener un aumento en sus jornales el mismo día que la huelga se derrumbaba en Caleta Buena.

En medio de estos sucesos, una comisión gubernamental había llegado al puerto iquiqueño con el objeto de resolver la conflictividad portuaria, en explícito resguardo de las entradas fiscales. Tras reunirse con las casas embarcadoras, el contratista y los diferentes gremios involucrados, los parlamentarios comisionados y el gobierno local presentaron un Reglamento para las faenas marítimas del puerto de Iquique, el 1 de diciembre, cuya aplicación trató de ser extendida por la provincia salitrera. Con el documento resolutorio, por cierto, no solamente fue ratificada la redondilla y la conformación arbitraria de las nuevas cuadrillas de jornaleros y estibadores (con la respectiva matrícula de rompehuelgas y la expulsión de trabajadores que la medida había implicado); sino que la decisión respecto de los obreros que compondrían tales cuadrillas le fue otorgada al mismo contratista monopólico que los trabajadores habían tratado de quitar de en medio, quien, naturalmente, seleccionó a "hombres afectos y otros que estaban sin trabajo". Por otra parte, en lo que a los cargadores respecta, también fueron duramente diezmados como sindicato; no únicamente por los despidos, sino por las nuevas condiciones laborales y salariales que los esquiroles aceptaron. Los lancheros, en tanto, consiguieron la demanda por el recorte en el horario de la jornada laboral, pero sufrieron también el raleo patronal entre sus filas. ${ }^{31}$

\footnotetext{
${ }^{30}$ Para todos los párrafos concernientes a esta huelga, además de los números de El Despertar de los Trabajadores correspondientes a las fechas indicadas, ver: "Relación circunstanciada de las dificultades suscitadas por los gremios de la gente de mar de esta Subdelegación Marítima entre los meses de Setiembre y Noviembre de 1916, según el Libro Diario de la Capitanía", en: Vol. 11-1916: Gobernación de Pisagua, 1916, numeración antigua de los volúmenes del Archivo de la Intendencia de Tarapacá (ITAR).

${ }^{31}$ Uno de los volúmenes de la Intendencia de Tarapacá contiene varias listas con trabajadores que las casas embarcadoras advirtieron no recibirían tras el conflicto. Juntas suman alrededor de ciento sesenta obreros que
} 
En el balance de este nuevo e incuestionable fracaso obrero, resulta obvio que el uso de las fuerzas armadas como estibadores resultó tan fatídico como determinante. No únicamente por reemplazar a los huelguistas, sino también por quebrar su unidad. Desde el punto de vista patronal, de hecho, romper la paralización del embarque de este modo en particular, les permitió a las compañías imponer condiciones laborales y salariales más favorables para sí, junto con deshacerse de obreros que les resultaban problemáticos. Por otra parte, la posición del contratista intermediario resultó fortalecida y sus hombres disciplinados. En el balance anual, en tanto, cuando el conflicto se desató, y el gobierno tuvo que interceder -fuese mediando o poniendo las tropas a disposición-, los favorecidos por el carácter estratégico de las exportaciones salitreras no fueron los obreros, sino los patrones.

Como lo probarían distintos incidentes ocurridos en Caleta Buena y Pisagua, sin embargo, los conflictos laborales no se apaciguarían durante los meses siguientes en los puertos tarapaqueños. La más importante de las huelgas, no obstante, en rechazo a una medida gubernamental que buscaba obligar a los trabajadores a fotografiarse para obtener sus matrículas, se inició fuera de Tarapacá y de manera espasmódica. Estalló primero en el también puerto salitrero de Antofagasta, el 31 de marzo, con cerca de mil obreros que detuvieron sus labores. Once días después, pese al número, la huelga fracasó y los trabajadores tuvieron que retratarse. Cinco días más tarde y por seis jornadas, quinientos portuarios iniciaron su propia huelga el 16 de abril en Valparaíso, por la misma razón pero con mejor suerte, consiguiendo que el gobierno retardara en tres meses el plazo final para el cumplimiento de la disposición. Esta prórroga permitió, tras otro paro en el puerto salitrero de Mejillones por el mismo motivo, que los trabajadores se citaran a una convención de carácter nacional con el objeto de confrontar el asunto del retrato forzoso. Problema que determinaron resolver paralizando las faenas en toda la costa chilena a partir del día 23 de julio y hasta que el decreto fuese abolido. ${ }^{32}$

En el caso de las provincias salitreras, el infatigable Sindicato de Cargadores de Iquique parece haber sido el primero en paralizar sus labores, aunque con una semana de retardo respecto de los puertos de la zona central. Les siguieron, durante la jornada siguiente, los lancheros del mismo puerto; y consecutivamente, los obreros de Junín, Caleta Buena y Pisagua. Resultado de lo cual, hacia el 1 de agosto, había diecisiete vapores con la carga de salitre paralizada en la provincia. En respuesta, la Intendencia notificó a las compañías salitreras que ya había dado la orden para que el Ejército y la Armada reemplazaran a cargadores y lancheros, y que dirigieran todos sus requerimientos a la Gobernación Marítima; orden que, para el 2 de agosto, se tradujo en alrededor de 150 hombres de la marinería y 270 del ejército haciéndose cargo de las faenas en Iquique. También en Pisagua, Caleta Buena y Junín, e igualmente en Mejillones. Pero no en Tocopilla, Coloso ni Taltal, donde los trabajos se realizaban con normalidad. En Antofagasta, en tanto, únicamente los lancheros, en número de cien, habían paralizado sus labores, y estaban siendo reemplazados por hombres traídos de la pampa. ${ }^{33}$

quedaban imposibilitados de volver al trabajo. En una segunda lista, de aproximadamente sesenta "obreros eliminados y cesantes que se han dirijido al sur", se repiten algunos nombres, pero no la mayoría, lo que obviamente incrementa el total. ITAR, Vol. 1047, legajos 170-179; 253-254.

32 Entre otros artículos del mismo periódico, ver: "La huelga general marítima", El Despertar de los Trabajadores, 25 de julio y 17 de agosto de 1917.

${ }^{33}$ ITAR 1041, Huelgas de Cargadores y Lancheros, Vol. 13-1917. 
A mediados de mes, sin embargo, los obreros de Valparaíso conciliaron con el gobierno y depusieron la paralización. Con las comunicaciones intervenidas entre los puertos salitreros y el comité de la huelga, radicado en dicha ciudad, el movimiento en el norte se volvió una especie de bestia ciega y herida, con coraje pero echada a su suerte. El 18 de agosto, por ejemplo, alrededor de 140 cargadores y 90 lancheros habían retornado al trabajo en Iquique, más un centenar de cargadores en Caleta Buena y Junín, y algunos lancheros en esta última localidad; pero los huelguistas iquiqueños escribían respecto de las preocupaciones en torno al puerto central: "Suponiendo que nuestros compañeros de Valparaíso salgan derrotados, el movimiento huelguista lo mantendremos [localizándolo] en la región salitrera". ${ }^{34}$ De cualquier modo, esta decadencia acompasada, tanto como el optimismo de los huelguistas, colapsarían el 23 de agosto por un atentado dinamitero fatal contra uno de los cuatrocientos conscriptos que realizaban las faenas portuarias. ${ }^{35}$ Los allanamientos, y sobre todo los encarcelamientos de obreros que el incidente permitió, se tradujeron en un nutrido número de hombres que trataron de volver a sus puestos; cuestión que, por dictamen de un gobierno provincial que decía actuar en nombre de la "libertad de trabajo", quedó en manos de las casas embarcadoras, significando nuevos contingentes de obreros eliminados. El eco de este tercer fracaso, por cierto, retumbó en toda la costa de la región del nitrato, poniéndole término a un parsimonioso desmoronamiento. ${ }^{36}$

En el balance de la huelga, tal como en la de octubre-noviembre de 1916, el empleo de las fuerzas armadas como rompehuelgas resultó fatal para desproveer a los obreros portuarios de la posición estratégica que, teóricamente, les brindaba ejercer y suspender su fuerza de trabajo en el cuello de botella de la exportación del nitrato, y para anular, por tanto, su efecto huelguístico: al ser prescindibles como trabajadores, los huelguistas resultaron desplazados fuera de la posición estratégica, haciendo su fuerza obrera irremediable y eficazmente socavada y pulverizada. Por otra parte, el aumento de accidentes laborales y la disminución de las huelgas durante 1918, parecen ser dos facetas e indicadores de que el recambio que las eliminaciones de hombres, durante las fracasadas huelgas de 1916 y 1917, había recaído precisamente entre el contingente laboral portuario más experimentado. Cuestión que debió incidir de modo importante, tanto cualitativa como cuantitativamente, en la gestación de movimientos reivindicativos desde los gremios portuarios.

\section{Las huelgas portuarias de 1919 y 1920}

Para estos obreros en los muelles salitreros, el paso de 1918 a 1919 estuvo signado por una brusca caída de las exportaciones de nitrato. Las 345.262 toneladas métricas embarcadas en octubre de 1918 bajaron a 230.426 en noviembre y a 154.341 en diciembre, descendiendo en enero de 1919 a 56.540, a 41.692 en febrero y a 35.943 en marzo, con un repunte pasajero en mayo (137.985) que se iría al suelo en julio, con la exportación de solo 22.641 toneladas. En términos anuales, siguiendo nuevamente a Couyoumdjian, 2.919.177 toneladas de salitre habían sido embarcadas por los puertos nortinos durante 1918, pero solo 803.961 toneladas lo fueron

\footnotetext{
34 "Los maquiavelismos del telégrafo", El Despertar de los Trabajadores, 21 de agosto de 1917.

${ }^{35}$ Sobre el atentado, ver: "Un saco de salitre explota en la Casa Gibbs", El Despertar de los Trabajadores, 24 de agosto de 1917.

${ }^{36}$ Ver: "Lección de hechos" y "Lección de hechos II: El arbitraje", El Surco, 22 de octubre y 29 de noviembre de 1917 respectivamente.
} 
durante 1919. ${ }^{37}$ Resulta obvio, por tanto, que en los puertos nortinos, el más evidenciable de los problemas que azotaban a la clase trabajadora hacia comienzos de este último año, fuera la escasez de trabajo. Lo que significaba también una abundancia de brazos todavía mayor que en 1916-1917 a disposición patronal.

No obstante, la falta de trabajo empujó igualmente a los jornaleros antofagastinos a parar las faenas dos veces en septiembre de 1919; de modo breve los primeros días, para frenar las convenientes preferencias de los capataces en la contratación, y la segunda, iniciada el día 17, para instaurar el "trabajo rotativo" como método para la estricta repartición del mismo. En esta última ocasión, a diferencia de la primera, la huelga de los jornaleros fue general en la bahía, estallando de manera organizada conjuntamente con los estibadores, lancheros, cargadores y movilizadores; manifestándose incluso los obreros de Mejillones en disposición de no efectuar ningún trabajo proveniente del puerto paralizado. Transcurrida una semana, y pese a que las iras de la prensa obrera develaban que algunos jornaleros y lancheros trataban de hacer los embarques, el paro estaba siendo lo suficientemente eficiente como para que la mayoría de los vapores comenzaran a dejar la bahía sin poder ser cargados. Únicamente entonces, el gobierno cedió al requerimiento de los trabajadores, y consiguió poner de acuerdo consigo a las firmas embarcadoras y a los contratistas para instaurar la redondilla como método de contratación y repartición del trabajo. ${ }^{38}$

Este resultado favorable, sin embargo, no significó la subyugación de los trabajadores, e inclusive tampoco el último de los logros obreros en la organización del propio trabajo. El 11 de octubre, conflictos con un capataz provocaron la paralización de los movilizadores en uno de los muelles, y cuando el conjunto de estos obreros se aprestaba a plegarse a la huelga, los jefes de las casas resolvieron hacer de la capatacía un puesto rotativo en manos obreras. Consideradas en conjunto, estas cuestiones significaban -teóricamente- el desmoronamiento del poder laboral de los contratistas en Antofagasta, basado en el control arbitrario de la contratación de la fuerza de trabajo mediante los capataces. Significó también, por cierto, un fortalecimiento del raquítico estado orgánico de los trabajadores de la provincia, haciendo de la Federación Obrera Marítima una organización compuesta por los obreros portuarios de los dos principales terminales marítimos de la provincia a mediados de noviembre: Antofagasta y Mejillones. A días de formada, la Federación salió airosa en una huelga general en los dos puertos, en solidaridad con los cargadores por razones salariales. En Taltal, por otra parte, el Consejo Federal de la Federación Obrera de Chile que aunaba a portuarios y ferrocarrileros encabezó una huelga que convirtieron en general hacia enero de 1920, forzando la cesión de la mayoría de las exigencias que habían presentado en un pliego conjunto, la derivación a arbitraje de las menos, y la reactivación de las faenas en cuestión de algunas horas.

A diferencia de la tragedia exportadora sufrida en el tránsito de 1918 a 1919, el de 1919 a 1920 mostró mejoras significativas. Los embarques de nitrato se incrementaron de 39.154 toneladas métricas en noviembre de 1919 a 229.677 en diciembre del mismo año, para alcanzar un récord de 415.815 toneladas en enero de 1920; año que registraría un total de 2.746.118

\footnotetext{
${ }^{37}$ Couyoumdjian, op. cit., 187.

${ }^{38}$ El Socialista destinó una cantidad importante de notas y crónicas a las huelgas portuarias de la Provincia de Antofagasta durante este período. Pueden consultarse los números que arrancan en "El conflicto de los jornaleros y la casa Stevenson", del 15 de abril de 1919, hasta "El colosal movimiento obrero en Taltal ha terminado", del 16 de enero de 1920.
} 
toneladas de salitre exportadas, muy por encima de las 803.961 de $1919 .{ }^{39}$ El mismo mes del récord apuntado, sin embargo, y pese a manifestar voluntad de conciliación en los conflictos laborales, el Ministerio del Interior expresó sus prioridades a la Intendencia de Tarapacá respecto de algunos incidentes en una de las casas embarcadoras de Iquique: "el gobierno desea y procura que no se interrumpa el embarque de salitre"; "si se produjera el paro de la jente mar ese embarque debe hacerse con la marineria o tropa de línea disponible (...) pagandoseles por los dueños del salitre que se embarque en iguales condiciones que a los demás obreros" (sic). Cuando la huelga estalló, el Ministerio ratificó telegráficamente: "Interes Gobierno es que no se retarde carguio salitre" (sic). ${ }^{40}$ En preservación de este ánimo, un conflicto en la casa Gildemeister hizo que el Gobernador Marítimo solicitara una treintena de soldados para reanudar las faenas en la bodega iquiqueña, y cincuenta más cuando los obreros de la Nitrate Agencies se sumaron en solidaridad. Desafortunadamente, la documentación es demasiado frágil para establecer los resultados de dichos conflictos.

En Antofagasta, hacia fines de marzo, un conflicto entre un capitán y una cuadrilla de lancheros, detonó un lockout que paralizó todas faenas de la bahía. Después de tres días, las compañías consiguieron imponer sus exigencias, expulsando a toda la cuadrilla e inmovilizando al resto de los trabajadores al dejarlos sin trabajo que paralizar. La dinámica se repitió durante los mismos días en Mejillones, donde un incumplimiento patronal provocó un conflicto que rápidamente devino en otro lockout, siendo incluso asistido por las fuerzas armadas. Como dijeron los propios obreros, que presumieron la premeditación y preparación de los conflictos, los papeles parecían haberse invertido. ${ }^{41}$

El mayor conflicto, no obstante, estalló a mediados de año, en junio de 1920. Los obreros portuarios de Iquique iniciaron una huelga con el propósito de reinstaurar la redondilla, que había conseguido ser desmantelada por los patrones tras 1916, despertando la solidaridad de otros puertos salitreros importantes. Primero fueron trabajadores de Mejillones los que boicotearon a los vapores que acudieron desde Iquique en busca de carga de salitre, cuestión que se convirtió en una huelga y un lockout que paralizaron totalmente las faenas hacia el día 18. Esta situación detonó sucesivamente la huelga en Antofagasta y en Coloso. En el primero de estos dos puertos, mientras las tropas comenzaban a ocuparse de las faenas en Iquique, la Compañía de Salitres expulsó a los trabajadores de la sección locomotoras, excusándose en lo prescindibles que los tornaba la huelga portuaria. Sin embargo, en vez de poner a trabajadores contra trabajadores, la medida patronal provocó la solidaridad de los obreros del ferrocarril de Mejillones, que manifestaron su disposición a plegarse a la huelga; punto en el que las tropas comenzaron a reemplazar a los portuarios antofagastinos. En Iquique, los "operarios de tierra" también comenzaron a sumarse a la movilización, y para el 24, lo hicieron los del ferrocarril de esta ciudad, adquiriendo un carácter bastante parecido a una huelga general; situación que la Intendencia trató de subsanar con el mismo método de los muelles, aunque solicitando "jente

\footnotetext{
${ }^{39}$ Couyoumdjian, op. cit., 275.

${ }^{40}$ Todos los entrecomillados corresponden a: ITAR, Vol. 1181, legajos 30-32, 35-38, 49, 54, 57 y 62.

41 "El cierra puertas de los patrones", El Socialista, 27 de marzo de 1920.
} 
especialista" (sic). ${ }^{42}$ Tensionando todavía más las circunstancias, cuando las faenas portuarias comenzaron a ser realizadas por conscriptos en Mejillones, estalló la huelga en Tocopilla. ${ }^{43}$

Para la segunda semana de julio, la documentación presenta alguna información cruzada respecto de obreros que habrían comenzado a retornar a las faenas en Iquique, pero también sobre algunas casas embarcadoras importantes presionando a las autoridades para resolver el conflicto, sugiriendo incluso la supresión de los contratistas intermediarios; ambición de larga data entre los obreros portuarios, que había sido enérgicamente resistida por las firmas tanto como por los gobiernos, y que los portuarios antofagastinos habían retomado audazmente para entonces. ${ }^{44} \mathrm{La}$ resolución del conflicto, sin embargo, primero en Iquique y luego en Antofagasta, no llegó a tanto. Aunque la huelga sí terminó de modo favorable para los trabajadores respecto de su demanda original -pues la redondilla fue instaurada en los puertos tarapaqueños tras una nueva comisión-, los intermediarios no fueron suprimidos. ${ }^{45}$

Para diciembre, y tras una nueva paralización en solidaridad con los trabajadores del carbón, otro conflicto se resolvió de modo favorable para los obreros portuarios. Pese a que los cargadores habían abusado de las casas embarcadoras en el cobro del tarifado, y juntas, dichas casas se mostraron dispuestas a desatar el lockout, éstas recularon en preferencia de la conciliación y consiguieron llegar a acuerdos con los demandantes. ${ }^{46}$

Considerando esta última fricción, pero sobre todo la huelga de mediados de año, 1920 se cerraba junto con un período bastante favorable para los trabajadores en comparación con los conflictos sufridos durante 1916-1917. Período que, retrospectivamente, se había abierto con las huelgas de septiembre de 1919 en Antofagasta. Notablemente, cuando dicho conflicto ocurrió, las exportaciones del nitrato provenían de los meses con los índices más bajos en su historia (22.641 toneladas en julio y sólo cinco más en agosto). El conflicto de junio-julio en Iquique, en cambio, que también había resultado beneficioso para los trabajadores, había estallado después de varios meses exportando diez veces las referidas cantidades de 1919, en un año que había comenzado con más de cuatrocientas quince toneladas exportadas en enero. Números que conducen a preguntar en qué medida la cantidad de flujo exportador fue un factor condicionante para los resultados y los ánimos huelguísticos.

Una respuesta plausible sería suponer que las condiciones de 1919 mermaron la capacidad patronal para responder de algún modo a las exigencias obreras, tornándose su reacción todavía más feble al extenderse la paralización por la provincia pese a los esfuerzos gubernamentales por reemplazar a los huelguistas. Pero esta argumentación no resuelve el hecho de que la falta de trabajo debería haber sosegado igualmente los ánimos obreros por paralizar la producción. A menos que se suponga que tales hombres asumieran el hambre de quedar sin trabajo como la única opción al hambre de no tenerlo únicamente por la potestad y conveniencia de los capataces

\footnotetext{
${ }^{42}$ ITAR, Vol. 1243, legajo 81.

43 "La huelga marítima” y “A los trabajadores de Antofagasta y público en jeneral”, El Socialista, 28 de junio de 1920.

44 "La huelga marítima", El Socialista, 8, 9 y 10 de julio de 1920.

45 "Se acerca la solución de la huelga marítima", El Socialista, 18 de julio de 1920 y Anexo 1, Boletín mensual de la Asociación de Productores de Salitre, "Informe de la comisión gubernativa compuesta de los Sres. Enrique Oyarzún, Julio Philippi y Juan Enrique Concha...”, Junio 1921, Circular Trimestral No. IX Valparaíso 1921, XXXIV-XLIV.

${ }^{46}$ ITAR 1199, Copiador de Telegramas, 1920-1921, legajos 108, 109, 111, 114 y 118; ITAR 1180, Ministerio del Interior, Vol. 20-1920, legajos 212 y 213; ITAR 1156, Delegación Fiscal de Salitrera, 1919-1920, legajos 40-44.
} 
e intermediarios; lo que no deja de ser probable. Por otra parte, dicha argumentación tampoco contribuye a explicar de manera sencilla el comportamiento patronal durante 1920; año de buen tráfico comercial en el que, no obstante, el empresariado portuario iquiqueño evidenció similares carencias para sobreponerse a la iniciativa huelguística, a diferencia de los años previos, pero también a diferencia de sus homólogos de Antofagasta durante los meses inmediatamente anteriores, donde desataron una verdadera ofensiva que sí les reportó réditos tras la instauración de la redondilla en dicho puerto. Una segunda respuesta, prestando atención precisamente a lo ocurrido a mediados de 1920, es asumir que, al margen de los índices exportadores, los trabajadores consiguieron asestar un golpe más contundente que el que pudo organizar el empresariado en las mismas condiciones. El cierre de los puertos de Antofagasta y Mejillones a los buques derivados del puerto en huelga, resulta un ejemplo sintético de esto, porque los trabajadores consiguieron interrumpir la estiba, no de modo definitivo, pero sí suficiente para impedir que las tropas normalizaran las faenas, empujando a las casas embarcadoras y al gobierno a considerar inclusive el desmonte de la estructura de contrataciones, para poner término a lo que debieron avizorar como un suelo fértil en paralizaciones venideras. No obstante, al ser declinado este asunto como condición por los iniciadores de la huelga, éstos mantuvieron el conflicto dentro de los márgenes de lo plausiblemente negociable, consiguiendo su objetivo sin forzar una nueva e impredecible escalada de agresividad.

En cualquiera de los casos, cabe destacar, resulta hasta cierto punto sorprendente que las cuadrillas que encabezaron este proceso de logros fuesen las mismas que, pocos años antes, habían visto diezmadas sus filas y sido desprovistas de sus más hábiles organizadores.

\section{Los nuevos fracasos obreros de 1921 y 1923}

Como en 1919, la vertiginosa caída de las exportaciones salitreras fue el más serio de los problemas para los obreros portuarios en 1921. Las 259.150 toneladas métricas exportadas en enero de este último año, cayeron a la mitad en marzo y a tan sólo 30.089 toneladas en julio, llegando a un máximo de repunte en diciembre, el que marcó $76.793 .{ }^{47}$ Entre marzo y mayo, esto causó estragos en localidades como Junín y Caleta Buena. Por los registros patronales, sin embargo, en puertos como este último, los trabajadores se hallaban férreamente unidos $\mathrm{y}$ controlando de facto la contratación mediante su Unión Gremial. Lo que se traducía en una capacidad de estos obreros -y de los jornaleros y lancheros en particular- para interrumpir las faenas de embarque, exigiendo aumentos tarifarios en medio de la carga de un buque, o forzar los ritmos del trabajo para obtener beneficios respecto de los pagos del sobretiempo. En puertos de mayor carga, como Iquique, la situación parecía ser la misma: "Basta decir, para formarse una idea de las condiciones en que se trabaja a bordo actualmente, que por cualquier asunto insignificante suspenden el trabajo por una o más horas [para hacer alguna petición]", indicó un delegado de la Asociación de Productores de Salitre quejándose de la Federación Obrera Marítima, también formada en dicho puerto; "El Gobernador Marítimo, aunque tiene autoridad sobre ellos, no puede tomar medida alguna", agregó, "pues sería motivo suficiente para que se produjera una huelga, lo que traería talvez una paralización completa en las faenas marítimas"

${ }^{47}$ Couyoumdjian, op. cit., 275. 
(sic). ${ }^{48}$ Quejas que se reiteraban con bastante exactitud en torno a las faenas portuarias de Pisagua, donde los agentes de la misma Asociación asumían la situación como la pérdida del derecho patronal de despedir o contratar obreros. ${ }^{49}$ Esto último, pese a una cantidad sin precedente de desocupados que abandonaban la pampa como consecuencia de las crisis de la industria: el 95\% de la población obrera de Tarapacá y Antofagasta hacia fines de $1921 .^{50}$

En Iquique, durante febrero de este año, la fracasada huelga ferroviaria -a la que también había contribuido la citada Federación Obrera Marítima, cabe destacar-, había puesto de manifiesto la actitud del nuevo gobierno (de Arturo Alessandri), al impedir enfáticamente el empleo de tropas como rompehuelgas, pese a lo evidentemente estratégico que resultaba este medio de transporte para los embarques y por tanto para el mismo fisco. ${ }^{51}$ Lo que es de suma importancia, porque imposibilitaba la principal y acostumbrada táctica gubernamental-patronal frente a las huelgas portuarias; poniendo dichos conflictos en otras condiciones a las desarrolladas en 1916-1920, en la medida que posibilitaba el uso de la posición estratégica en la que los obreros portuarios teóricamente se hallaban.

Sin embargo, y durante meses, los telegramas nerviosos sobre tensiones laborales en muelles y bodegas fueron reemplazados por largas listas de obreros portuarios desocupados, ${ }^{52}$ mientras que los conflictos laborales se desplazaron al sur de los puertos salitreros, concentrándose en torno a la capacidad de los Trabajadores Industriales del Mundo (IWW) en Valparaíso para arrancarles diferentes mejoras tarifarias y vinculadas con la contratación a los comerciantes porteños, los que eventualmente conformaron una Asociación desde la cual pudieron negociar colectivamente y desarrollar una dura ofensiva cuando aquellos convenios no fueron respetados. ${ }^{53}$

Tras ser desatada, dicha ofensiva repercutió entre los obreros portuarios nortinos, y de Antofagasta en particular, en dos modos diferentes. Por una parte, los lancheros y los cargadores de este puerto interrumpieron los embarques en solidaridad con los hombres de Valparaíso, paralizando las faenas y azuzando el lockout patronal, con la consecutiva apertura de bolsas de trabajo excluyentes para los obreros federados. Por otra, esto último significó la derogación de facto de la redondilla mediante la cual trabajaban los jornaleros y estibadores desde 1919; pese a que estos obreros en particular se habían negado a prestar solidaridad de ningún tipo a sus apremiados congéneres de la zona centro, e inclusive se habían puesto a disposición de los patrones cuando éstos iniciaron el lockout. Dicha derogación se hizo oficial gubernamentalmente- el 24 de octubre, provocando una huelga que se mostró inútil por parte obrera contra las medidas legislativas, tornándose fatal para los agremiados, que volvieron a ser

\footnotetext{
${ }^{48}$ Boletín mensual de la Asociación de Productores de Salitre, "Carta recibida de nuestro delegado en Iquique", de fecha 19 de marzo de 1921, Junio 1921, Circular Trimestral No. IX Valparaíso 1921, XXIX-XXXII.

49"Carta de nuestros Agentes en Pisagua, señores Harrington, Morrison y Compañía”, Boletín mensual de la Asociación de Productores de Salitre, Circular Trimestral No. IX Valparaíso 1921, XXVI-XXVII.

${ }^{50}$ Julio Pinto Vallejos, Desgarros y utopías en la pampa salitrera. La consolidación de la identidad obrera en tiempos de la cuestión social (1890-1923), Santiago, LOM Ediciones, 2007, 161.

51 "La gran huelga ferroviaria” y "Al tribunal de la conciencia pública", El Despertar de los Trabajadores, 21 de enero de 1921.

52 ITAR, Vol. 1229 y Vol. 1209.

${ }^{53}$ Los conflictos de Valparaíso tienen una documentación imposible de reducir en un pie de página, pero han sido trabajados en: Santibáñez Rebolledo, op. cit., 107-118.
} 
ignorados en la repartición de trabajo por mano de los intermediarios. Situación, por cierto, que fue replicada en el vecino puerto de Mejillones. ${ }^{54}$

En Iquique, en cambio, los delegados porteños de la IWW no habían conseguido provocar el boicot a los vapores provenientes de Valparaíso en solidaridad durante septiembre. Según el infiltrado agente policial de pesquisas, "la opinión casi unánime de los trabajadores [había sido] contraria a esta idea, por la crítica situación pecuniaria en que se [encontraban] los obreros de estas faenas". ${ }^{55}$ Reacción que, no obstante, varió tras enterarse los trabajadores de la derogación a la redondilla antes referida; pero que también fue posibilitada, aparentemente, por condiciones de exportación que duplicaban las que habían tenido en primavera, cuando estalló el conflicto en la zona central del país. Pese a esto, y por alguna razón no sencilla de precisar, la redondilla perduró en los muelles iquiqueños tras haber sido abolida en Antofagasta, y su excepcionalidad fue ratificada legislativamente el 28 de abril de 1922, convirtiéndose en el bastión a tumbar para las casas embarcadoras; en condiciones diferentes, por cierto, a las que habían tenido en 1916$1920 .^{56}$

Previsiblemente, esto hizo de 1922 un año de tensiones, signadas por un palpable arrinconamiento por parte del Gobernador Marítimo a los gremios de este puerto salitrero; intencionalidad deducible a partir de mermas arbitrarias en los jornales y la cancelación selectiva de matrículas a algunos wobblies. Según planteaban estos últimos, se trataba de una situación imposible, pues, si los jornaleros y estibadores no reaccionaban a las provocaciones, el Gobernador terminaría por cancelarles la matrícula a todos los obreros capaces de organizar una respuesta; si, en cambio, reaccionaban con una huelga, la redondilla figuraría como facilitadora de las paralizaciones, resultando más sencillo bregar por su derogación. ${ }^{57}$ No obstante, los hostigamientos se ampliaron, comenzando a recaer sobre los lancheros que eran parte de la IWW, en forma de multas y suspensiones. El acoso que hizo estallar el primer conflicto, sin embargo, fue sobre los jornaleros de la descarga del carbón, por un recorte salarial ordenado por el Gobernador, el 11 de noviembre, que se convirtió en un boicot a propósito del cual los empresarios salitreros efectivamente exigieron la derogación de la redondilla. Para fines de mes los jornaleros plegados al boicot y consecuentemente sancionados por el Gobernador eran tantos que el puerto estaba paralizado. ${ }^{58} \mathrm{El}$ aplastamiento con una lingada sobre un muchacho de 17 años que se ocupaba habitualmente de la costura de sacos, prueba que las casas embarcadoras trataron de reemplazar a los jornaleros con cualquier hombre que tuviesen a mano. ${ }^{59}$ Como fuere, lo cierto es que esta especie de lockout gubernamental provocó un atochamiento de embarques que terminó por venirse abajo, y que tuvo por resultado la anulación de los castigos y el pago de

\footnotetext{
54 "El criterio de los obreros organizados y los rumbos de una Empresa Periodística", El Despertar de los Trabajadores, 28 y 31 de enero, y 4, 5 y 7 de febrero de 1922; Gobernación Marítima de Antofagasta al Director del Territorio Marítimo en Valparaíso, ARNAD, Oficina del Trabajo, Vol. 70, Comunicaciones recibidas del Interior, 1921, Vol. III (3 Vols.), Antofagasta, 4 de octubre de 1921.

55 ITAR, Vol. 1234, legajo 171.

${ }^{56}$ Arturo Acevedo, El problema de las faenas marítimas en la zona salitrera. El sistema de redondilla y la nueva reglamentación, Talcahuano, Librería e Imprenta Moderna, 1923.

57 “Abusos autoritarios”, El Productor, 29 de julio de 1922.

58 “Un grave conflicto en la bahía provocado por el Gobernador Marítimo”, El Despertar de los Trabajadores, 25 de noviembre de 1922.

59 "El Conflicto causado por el Gobernador Marítimo”, El Despertar de los Trabajadores, 28 de noviembre de 1922.
} 
lo adeudado a los jornaleros. ${ }^{60}$ Durante el mes siguiente, en Iquique, una amenaza de paralización del gremio de lancheros logró levantarles la suspensión a dos de estos, pero en la cercana localidad de Punta de Lobos, y pese a la solidaridad entre cargadores y lancheros, el mismo método terminó con la expulsión de los veintidós huelguistas involucrados; resultados que probaban, nuevamente, que no habían condiciones generales que determinaran las consecuencias de las huelgas. ${ }^{61}$

En marzo de 1923, la expulsión de un cargador de la IWW provocaría un nuevo paro que se trenzaría con la intención de los lancheros -también wobblies- por nombrar un inspector propio en todas las casas; ambas cuestiones en Iquique. La paralización de los primeros y las amenazas de los segundos, les reportaron rápidos réditos a los trabajadores de la Unión Local. ${ }^{62}$ Dos meses más tarde, pero en Pisagua, otro conflicto terminaría en huelga, por el desconocimiento patronal del tarifado acordado. Iniciada la paralización, un conjunto de obreros fueron suspendidos y otros expulsados; cuestión que no debilitó tanto la huelga como la escasez de trabajo que paralizar, siendo el conflicto económicamente soportado por los obreros iquiqueños. El 9 de junio la paralización se resolvió porque ambas partes cedieron: los obreros a sus pretensiones salariales y el Subdelegado Marítimo de Pisagua a las medidas tomadas, dejándolas sin efecto pero decretando que cualquier intento de paro significaría su aplicación. La Unión Local de Iquique, sin embargo, le contestó a la autoridad que, de atreverse, todos los gremios portuarios iniciarían una huelga general. ${ }^{63}$

El 1 de agosto, con motivo de un conflicto de atribuciones entre la Gobernación Marítima y el Gremio de Jornaleros y Estibadores respecto de los obreros que podían trabajar en las faenas portuarias, y de la permanencia de un inspector (también wobblie) que dicha autoridad quería remover, los jornaleros iniciaron un boicot sobre los buques salitreros. En el puerto, y no obstante los intentos de algunas tripulaciones por suplir la falta de hombres, la Gobernación Marítima publicó llamados en búsqueda de brazos suplentes; lo que empujó a cargadores y lancheros a unirse a la huelga, quedando de este modo paralizadas todas las faenas. Sin embargo, y cuando comenzaban los primeros boicots en solidaridad en otros puertos, la resolución fue mediada, obteniendo los trabajadores un ambiguo resultado que involucró la remoción del wobblie de su cargo. $^{64}$

Menos de dos meses más tarde, y originado en la separación gubernamental de otro wobblie de las faenas de estiba iquiqueñas, estalló el último y más prolongado conflicto laboral de los muelles iquiqueños de este ciclo huelguístico. El conjunto de los jornaleros decretaron la huelga el 24 de septiembre, siendo secundados por los estibadores, lancheros y cargadores, y el 25 el gobierno decretó la supresión de la redondilla en este puerto. ${ }^{65}$ Para entonces, las casas embarcadoras ya habían colocado un inserto en la prensa, convocando trabajadores para

60 "El mas completo triunfo de los trabajadores marítimos", El Despertar de los Trabajadores, 7 de diciembre de 1922.

61 "Uno tras otro" y "De Punta Lobo", El Sembrador, 16 de diciembre de 1922.

62 "Nigromancia comunista", El Sembrador, 24 de marzo de 1923; ITAR 1203, Archivo Confidencial, 1920-1923, legajos 138, 142-143, 146-147.

63 "La huelga de los trabajadores marítimos de Pisagua", El Despertar de los Trabajadores, 10 de mayo de 1923 y "La huelga de Pisagua", El Sembrador, 12 de mayo de 1923.

${ }^{64}$ ITAR 1203, Archivo Confidencial, 1920-1923, legajos 203 y 108-110.

65 "La separación del obrero marítimo Francisco Miranda es un grosero atentado a la constitucion", El Despertar de los Trabajadores, 25 de septiembre de 1923. 
componer las nuevas cuadrillas de jornaleros y estibadores; enrolamiento para el que dispusieron del debido resguardo policial. ${ }^{66}$ Pese a esto último, la medida no tuvo buenos resultados, y las casas comenzaron a evaluar la posibilidad de hacer los embarques de salitre por Pisagua, Caleta Buena y Junín; puerto, este último, donde los cargadores habían comenzado simultáneamente una huelga por motivos salariales, con el respaldo huelguístico de los lancheros, jornaleros y estibadores locales. $^{67}$

Corroborando los malos resultados del reclutamiento una vez iniciado octubre, las casas embarcadoras comenzaron a ofrecer incentivos para el conseguimiento el permiso y la libreta de matrícula. ${ }^{68}$ La represión gubernamental recrudeció sobre los huelguistas, siendo allanados los locales sindicales portuarios y buen número de estos obreros encarcelados. Para mediados de octubre, los trabajadores portuarios de Antofagasta, Taltal, Tocopilla, Junín y Pisagua se hallaban paralizados en respaldo a los obreros de los muelles iquiqueños. ${ }^{69}$ Es posible datar, no obstante, sobre la misma fecha, un mejoramiento irreversible de la capacidad de carga en dichos muelles. A inicios de noviembre, más de trescientos hombres repartidos en las faenas conseguían estibar cerca de 1.500 toneladas de nitrato; cantidad que a mediados del mismo mes ascendía a 2.400 con el mismo número de obreros. Para inicios de diciembre, el retorno de los lancheros a las faenas hizo crecer exponencialmente el número de trabajadores laborando a casi novecientos, y su capacidad de estiba a 7.450 toneladas. $^{70}$

En Pisagua, en tanto, las faenas eran realizadas por los presos a comienzos de noviembre, y en Junín, los dirigentes de la huelga habían sido expulsados para la misma fecha. Considerando que Caleta Buena no se había sumado a la solidaridad huelguística, el panorama tarapaqueño era bastante desalentador. Durante este mismo mes, la violencia entre huelguistas y esquiroles ya había cobrado algunos muertos en Iquique y la comisión gubernamental había arribado y partido del mimo puerto, sin ningún otro resultado que exhibir la dureza de la posición patronal por eliminar a los huelguistas y retomar el control sobre la contratación; un amarre de doble nudo para la prevención de futuras paralizaciones. ${ }^{71}$

Para el 10 de diciembre, cuando más de setenta obreros eran devueltos a sus casas por estar todos los puestos de trabajo cubiertos, las faenas portuarias se dieron por normalizadas. Pese a que el día siguiente eran rechazados el doble de trabajadores, los huelguistas insistían en la posibilidad de revertir la situación. ${ }^{72}$ No obstante, ni siquiera la solidaridad (económica)

\footnotetext{
66 “Aviso" y "Se agrava el conflicto maritimo", El Nacional, 24 de septiembre de 1923.

67 “Caleta Junín”, El Sembrador, 29 de septiembre de 1923.

68 “Los salitreros no aceptan la restauración”, El Nacional, 2 de octubre de 1923.

69 "La huelga de los trabajadores marítimos" y "El movimiento huelguista a traves de los puertos salitreros", El Despertar de los Trabajadores, 18 de octubre de 1923.

70 "1200 toneladas de salitre se embarcaron hoy", 5 de noviembre de 1923; "Las faenas de la ribera", 21 denoviembre; "Actividades marítimas", 7 de diciembre; y "30 barcos en la bahia", 15 de diciembre de 1923, todas las noticias corresponden a El Nacional.

${ }^{71}$ Prácticamente todos los números de El Despertar de los Trabajadores y de El Sembrador durante octubre y noviembre hacen referencia a la situación mencionada. Sobre la situación fuera de Iquique ver: "De la huelga", $E l$ Sembrador, 3 de noviembre de 1923, "Bajo la presión de la fuerza se hace volver al trabajo a los obreros de Junin", El Despertar de los Trabajadores, 25 de octubre de 1923 y "En Pisagua se esta haciendo trabajar a los presos de la cárcel", El Despertar de los Trabajadores, 2 de noviembre de 1923.

72 "En la bahía", "Hoy trabajaron 617 hombres", "Actividades Marítimas" y "El sistema de redondilla", El Nacional, 4, 10, 11 y 12 de diciembre de 1923 respectivamente.
} 
desplegada por la Federación Obrera de Chile a lo largo de la pampa tuvo algún efecto en el devenir de la huelga, reconociendo, dos días más tarde y en su propio periódico, el fracaso de la extensa paralización. ${ }^{73}$ Considerando que la comunicación oficial no ocurrió hasta el día 19, la huelga había durado noventa días. ${ }^{74}$ Su desastroso resultado había sido el retorno del control de la contratación a manos patronales. ${ }^{75}$

Considerando el período abierto con la ofensiva patronal de 1921, el balance de estos conflictos arroja un par de elementos relevantes al análisis. En primer término, la señal gubernamental de no permitir el empleo de tropas como rompehuelgas, durante la escasa exportación del nitrato de 1921, parece haber atenuado los impulsos patronales tarapaqueños; aunque no los de la vecina provincia de Antofagasta, como demostraron en la primavera del mismo año al decretar el lockout y abrir la bolsa de trabajo, retomando el control de la contratación. En Tarapacá, en cambio, la reticencia a provocar conflictos que terminaran paralizando las faenas, parece haber sido aprovechada por los obreros para conseguir algunas concesiones con la sola amenaza de interrupción de los embarques; siendo esto el resultado de lo que significaba controlar la contratación en el gollete mismo del cuello de botella exportador (o de llevarla al límite de lo soportable). Lo segundo es que, para 1922 y 1923, el insistente acoso sobre algunos portuarios miembros de la Unión Local de Iquique por parte de la Gobernación Marítima, pone en evidencia al menos dos cosas: una, que la IWW había conseguido congregar en torno a sí a los gremios portuarios y dirigir aquella unión con propósitos reivindicativos (o al menos la citada Gobernación estaba lo suficientemente convencida de ello); y dos, que las pretensiones gubernamentales locales de Tarapacá no parecen haber coincidido con las del empresariado portuario hasta fines de septiembre de 1923, permaneciendo todavía, estos últimos, reticentes a provocar conflictos; al punto incluso de contribuir a derogar las represalias que la Gobernación Marítima había impuesto a los obreros y que mantenían paralizado el puerto de Iquique hacia noviembre de 1922. A fines de septiembre del año siguiente, en cambio, pese a que la huelga de los noventa días obligó a las casas embarcadoras tarapaqueñas a arreglárselas sin tropas para destrabar la paralización (cuando esta fue detonada nuevamente por el hostigamiento de la Gobernación), el hecho que la derogación gubernamental de la redondilla aconteciese de manera simultánea a la convocatoria para la formación de nuevas cuadrillas por parte de las casas embarcadoras, sugiere que ambos agentes, empresariado y gobierno, pudieron haber coincidido en las ansias de asegurar el flujo mercantil tanto como en la preparación del conflicto para conseguir la normalización de dicho flujo por un buen tiempo. Considerando que era hasta cierto punto previsible, por la imposibilidad de recobrar el funcionamiento usual de las faenas con tropas, tres meses de huelga debieron ser una dura prueba en tiempos de poca paciencia para los exportadores; únicamente soportable, cabe suponer, por la consecución de un objetivo como la recuperación del control de la contratación, cuya garantía no podía brindar sino el gobierno. En caso contrario, de no haber existido la asumida coordinación, la habilidad patronal para asestar dicho golpe en el momento preciso, y mantenerse firmes pese a las circunstancias, resultaría una impecable muestra de tenacidad táctica.

\footnotetext{
73 "Despues de redactado el decreto que restablecía la redondilla, el Presidente se negó a firmarlo", El Despertar de los Trabajadores, 14 de diciembre de 1923.

74 "El anuncio oficial del fin de la huelga", El Nacional, 18 de diciembre de 1923.

${ }^{75}$ ITAR 1203, Archivo Confidencial, 1920-1923, legajos 124-127.
} 


\section{Conclusiones}

Consideradas como parte de un mismo ciclo, la revisión de estas huelgas permite un par de apuntes conclusivos y otros hipotéticos. En primer término, resulta bastante evidente que los hombres que laboraban en los muelles tarapaqueños no eran en 1916-1923 lo imprescindibles que habían sido o parecían en 1887. En 1916-1923 fueron comúnmente reemplazados por soldados y por otros obreros, tomando estos últimos buena parte del lugar que las purgas patronales dejaron en las cuadrillas tras las huelgas. Si bien no es el propósito de este escrito hacer un estudio comparativo entre dichos períodos, y pese a no contar con un estudio acabado de las condiciones tecnológicas del embarque del salitre para fines del siglo XIX, resulta plausible sostener, a partir de los grabados de tales faenas en Iquique o Pisagua y otros registros de tipo historiográfico ${ }^{76}$, que la introducción de tecnología portuaria, aunque se redujera a canales por los cuales arrojar los sacos traídos de la pampa o las bodegas por carros enrielados, había resultado importante a efectos de prescindir totalmente de los fornidos hombres del siglo XIX. Según los registros anteriormente revisados, sin embargo, dichos cambios y efectos parecen haber sido privativos de puertos como Iquique, pues en el caso antofagastino, las importantes huelgas de 1919 no fueron sofocadas con rompehuelgas ni con tropas, y el único caso de reemplazos antes de 1920 ocurrió con los lancheros, en 1917; faenas éstas que, reforzando el acento en el rol de lo tecnológico para el desfonde de la fuerza huelguística, también habían incorporado tecnología para subsanar los esfuerzos descomedidos realizados por tales trabajadores (mediante la introducción de remolcadores).

Por otra parte, estas premisas hacen de la huelga de junio de 1920, en Iquique, un triunfo obrero anómalo que requiere explicaciones particulares; la primera de las cuales parece ser la capacidad obrera de extender la paralización hacia otros puertos importantes, y precisamente, sobre la provincia de Antofagasta. En este último puerto, donde no habían sido introducidas mejoras tecnológicas significativas, con la excepción del lanchaje, el reemplazo con tropas fracasó. Situación de la que puede inferirse, entre otras cosas, la importancia de las capacidades orgánicas a partir de las cuales las condicionantes tecnológicas locales podían ser desbordadas. Mismo supuesto lógico que cabría hacer en torno a la fallida huelga de 1921 en Antofagasta, cuyo fracaso habría sido abonado por la división entre las propias filas obreras. En 1922-1923, por otra parte, los obreros iquiqueños, replegados y pujando por fortalecer la Unión Local de la IWW, apelaron a dominar el control de la contratación; fallando, por cierto, y siendo arrasados. Esto último, pese al impedimento de hacer uso de las fuerzas armadas como rompehuelgas.

En suma, como fuerza de trabajo, los obreros portuarios en los muelles nortinos ciertamente eran un eslabón clave para la estratégica industria exportadora salitrera durante 19161923 y particularmente vulnerable para su circuito de circulación; pero esto no les significaba a

\footnotetext{
${ }^{76}$ Por ejemplo, refiriéndose a las labores de fines del siglo XIX, otros investigadores han sostenido: "En la playa, desde los almacenes hasta los lanchones varados a distancia prudente del fondo arenoso, en un trayecto que consistía en varias decenas de metros cuando menos, los obreros debían transportar sobre sus hombros 'sacos de material que llegaban a pesar hasta siete quintales españoles', vale decir, 138 kilos, con el agravante que la faena misma debía de ser realizada teniendo el obrero el agua hasta la cintura"; situación que no parece haber sido lo común para el período abarcado en este artículo. En: Carlos Parker y otros, "Perspectiva del desarrollo histórico de las organizaciones de los obreros marítimos chilenos", Memoria para optar al título de Profesor de Estado en Historia y Geografía, Pontificia Universidad Católica de Valparaíso, 1985, 15.
} 
dichos obreros una posición estratégica, pues, como hombres, eran, a fin de cuentas, prescindibles para la realización de tales faenas. Desplazados fuera de dicha posición, de hecho, al desatarse las paralizaciones de los embarques, por huelgas o lockouts, éstas afectaron a tales obreros de manera distinta pero igualmente dura en ambas provincias salitreras, reportándoles, como trabajadores, más daños que resguardos. Pese a lo cual, cabe señalar, las huelgas no dejaron de brotar de las cuadrillas raleadas, consiguiendo algunas concesiones de parte de patrones que prefirieron no tener que incurrir en los ajetreos propios de resolver paralizaciones cuando éstas podían evitarse.

Para puertos particulares e importantes, como Iquique, lo señalado en el párrafo previo insta a plantear como hipótesis que, no obstante haber sido la interrupción de las faenas una táctica forjada cuando le reportaba garantías negociadoras a los estibadores del salitre (dicho en grueso, durante el siglo XIX), estos obreros parecen haber mantenido la propensión a paralizar el trabajo cuando dicho método dejó de garantizarles triunfos, posibilitados inicialmente por la precariedad de la infraestructura, pero aminorados de manera importante por los mejoramientos parciales de la misma. Es decir, una falencia obrera respecto de los propios métodos y su efectividad. Lo que, por otra parte, empuja a preguntar si dicha modernización no fue sino una expresión tecnológica de la lucha de clases en los puertos nortinos, en tanto que esfuerzo patronal por socavar dicha posición estratégica, basada en la capacidad de tales hombres para resolver la precariedad de la infraestructura con la propia fuerza física, que, por definición, paralizaban a voluntad. Cosa semejante ocurre respecto de la creación de reglamentaciones y decretos para la regulación de las faenas portuarias, en tiempos carentes de legislación laboral.

Esto obliga también a advertir una cuestión que, pese a no ser considerada en los cálculos primarios de Womack Jr., resulta fundamental en el estudio de los conflictos laborales y portuarios en particular. Partiendo de la base que las paralizaciones en los muelles podían provocar verdaderas trombosis a las exportaciones del nitrato, la capacidad de infligir daño no era, en 1916-1923, una atribución exclusiva de los obreros sobre el empresariado salitrero y embarcador mediante huelgas; sino también por parte de estos últimos contra los trabajadores, a través de lockouts. Esta capacidad de paralización le confirió una posición estratégica crucial al empresariado, que ocuparon numerosas veces y con gran efectividad en los puertos salitreros durante el período en estudio, consiguiendo remover, de hecho, a los obreros de las faenas, y por tanto de sus posiciones teóricamente estratégicas.

En ello, y de distintos modos, el rol estatal fue determinante durante buena parte del proceso, en evidente favor patronal; poniendo a las fuerzas armadas o a los presos a disposición de las firmas embarcadoras, ejecutando abiertamente la represión contra los trabajadores y sus organizaciones, o permitiendo que las gerencias apartaran a los hombres que consideraban "agitadores" de las bodegas, muelles y barcos. La legislación referida algunas líneas antes, por otra parte, no hizo sino terminar de socavar una abatida e inutilizada "posición estratégica", que no había conseguido tornar la vulnerabilidad de la válvula exportadora en una fuerza obrera capaz de imponer los propios términos en los conflictos laborales que desataba, o era empujada a asumir. Cuestión que implicó el retroceso, al término del ciclo huelguístico, de los avances que los trabajadores habían conseguido en el breve 1919-1920.

En síntesis, las posiciones estratégicas, según pone de relieve este conjunto de huelgas portuarias, no pueden estudiarse únicamente "con el ojo de un ingeniero", como planteara Womack Jr., ni "[centrándose] sólo en los barcos, la carga, los medios para moverla y cómo los 
trabajadores la usaban para cargar y descargar". ${ }^{77}$ Pues, pese a la centralidad de dichos aspectos para la comprensión de los conflictos laborales, es fundamental considerar estas posiciones estratégicas, técnicamente posibilitadas, como históricas; es decir, que preceden a los hombres que se hallan en ellas, al mismo tiempo que éstos bregan por organizarlas en alguna medida a su favor, atizando la capacidad de los diferentes agentes involucrados para torcer o socavar dichas posiciones estratégicas por vías no únicamente tecnológicas. La disputa por la redondilla, de hecho, a lo largo de todo el ciclo huelguístico de 1916-1923, evidencia que el control sobre la composición de las cuadrillas fue la más recurrente de dichas vías.

Por lo mismo, el estudio de las posiciones estratégicas para comprender la anatomía y los resultados de los conflictos laborales, no debiese dejar de considerar que tales posiciones son también el motivo y la razón del estallido de una parte clave de estos conflictos. Porque siendo el propósito de los agentes confrontados apropiarse de dichas posiciones estratégicas, o desplazar a otros de las propias, los conflictos laborales adquieren formas particulares (como lo evidencia la exagerada prolongación de huelgas por cuestiones en apariencia menores), y transforman, al mismo tiempo y severamente, el común mundo del trabajo del que son parte (provocando, por ejemplo, cambios sustantivos en los sistemas de contratación). El estudio histórico de tales transformaciones, de hecho, permitiría examinar procesos de más larga duración que coyunturas como la aquí investigada, sin abandonar el entramado conflictivo que las explica como parte de una misma y tensionada hebra laboral.

\section{ANEXO}

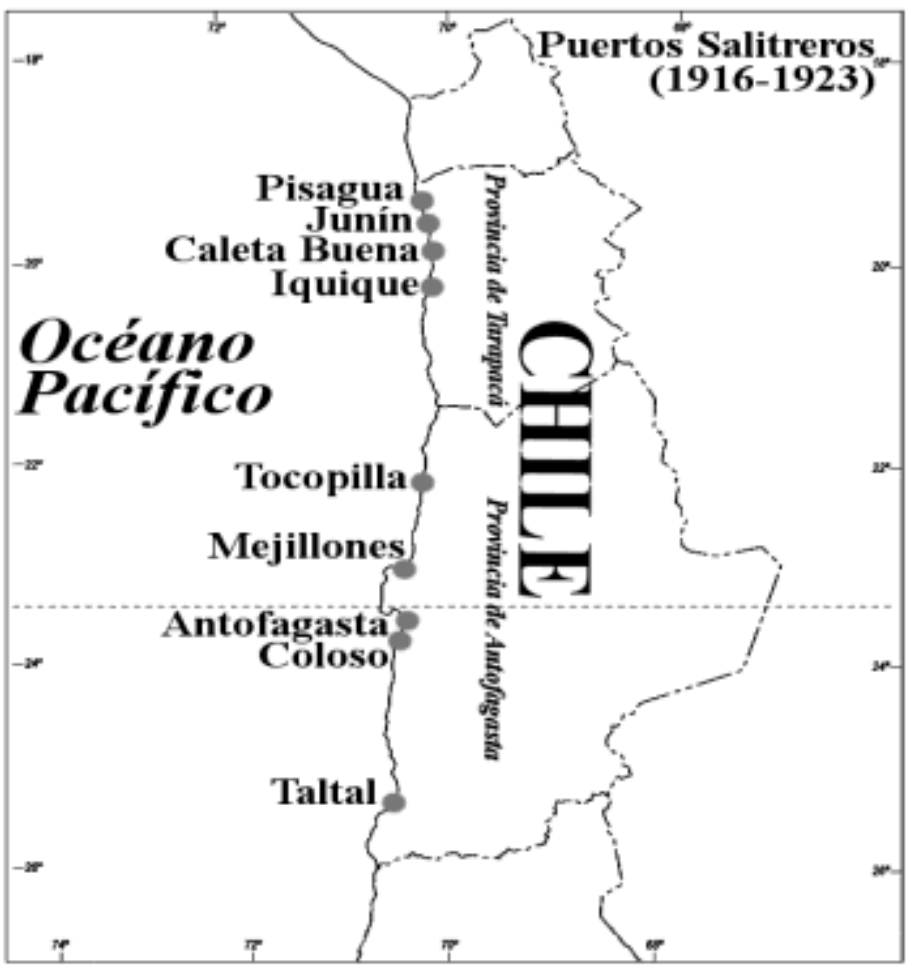

${ }^{77}$ Womack Jr., op. cit., 21. 


\section{BIBLIOGRAFÍA Y FUENTES}

\section{Libros y artículos}

Aguiar, S., "El concepto de 'posición estratégica'. Reseña de un libro y avances de una investigación", Cuadernos de Estudios del Trabajo, N²12, Santiago, 2009.

Cooper, F., "Dockworkers and labour history", Colin Davies, Dock workers. International Explorations in Comparative Labour History, 1790-1970, Aldershot-Vermont, Ashgate, 2000, 523-541.

Couyoumdjian, J. R., Chile y Gran Bretaña durante la Primera Guerra Mundial y la Postguerra, 19141921, Santiago, Editorial Andrés Bello/Ediciones Universidad Católica de Chile, 1986.

González Miranda, S., “Normalización' de la crisis y posición estratégica empresarial durante la expansión de la economía del salitre”, Polis, Revista Latinoamericana, №14, Vol. 40, Santiago, 2015, 397-419.

Grez Toso, S., De la "regeneración del pueblo" a la huelga general. Génesis y evolución histórica del movimiento popular en Chile (1810-1890), Santiago, RIL, 2007.

Hobsbawm, E. J., "National Unions on the Waterside", Eric J. Hobsbawm, Labouring Men. Studies in the History of Labour, Londres, Weidenfeld and Nicolson, 1964, 241-271.

Matus González, M., "Fulgor y muerte del jornal salitrero en Chile, 1899-1930", Sergio González Miranda, La Sociedad del salitre. Protagonistas, migraciones, cultura urbana y espacios públicos, 1870-1940, Santiago, RIL, 2013, 503-534.

Parker, Carlos, Sergio Valenzuela y Germán Ávalos, "Perspectiva del desarrollo histórico de las organizaciones de los obreros marítimos chilenos", Memoria para optar al título de Profesor de Estado en Historia y Geografía, Pontificia Universidad Católica de Valparaíso, 1985.

Pinto Vallejos, J., "La transición laboral en el norte salitrero: La provincia de Tarapacá y los orígenes del proletariado en Chile 1870-1890", Historia, Vol. 25, Santiago, 1990, 207-228.

Pinto Vallejos, J., "En el camino de la mancomunal: organizaciones obreras en la provincia de Tarapacá, 1880-1895", Cuadernos de Historia, º14, Santiago, 1994, 81-135.

Pinto Vallejos, J, "La transición laboral en el norte salitrero: La provincia de Tarapacá y los orígenes del proletariado nacional (1870-1890)", Julio Pinto Vallejos, Trabajos y rebeldías en la pampa salitrera. El ciclo del salitre y la reconfiguración de las identidades populares (1850-1900), Santiago, Universidad de Santiago de Chile, 1998, 23-54.

Pinto Vallejos, J., "En el camino de la mancomunal: Organizaciones obreras en la provincia de Tarapacá (1880-1895)", Julio Pinto Vallejos, Trabajos y rebeldías en la pampa salitrera. El ciclo del salitre y la reconfiguración de las identidades populares (1850-1900), Santiago, Universidad de Santiago de Chile, 1998, 153-226.

Pinto Vallejos, J., Desgarros y utopías en la pampa salitrera. La consolidación de la identidad obrera en tiempos de la cuestión social (1890-1923), Santiago, LOM Ediciones, 2007.

Santibáñez Rebolledo, C., "Huelgas y lockouts portuarios por la redondilla. Los conflictos por el control de la contratación en los muelles chilenos (1916-1923)", Tesis inédita para optar al grado de Magíster en Historia, mención Historia de Chile, por la Universidad Santiago de Chile, Santiago, 2015.

Venegas, H., "De imprescindibles a marginados. Las movilizaciones de los trabajadores del carbón en Chile a mediados del siglo XX”, Tiempo Histórico, N³, Santiago, 2011, 105-126.

Venegas, H., "Anticomunismo y control social en Chile, la experiencia de los trabajadores del carbón en Lota y Coronel, a mediados del siglo XX", Revista de Historia Social y de las Mentalidades, $\mathrm{N}^{\circ} 16$, Vol. 2, 2012, 79-106. 
Venegas, H., "La posición estratégica de los trabajadores del carbón en Chile. De su fortaleza a la crisis, 1920-1960", Anos 90, N¹9, Vol. 35, Porto Alegre, 2012, 445-474.

Villalobos, S., Historia de la Ingeniería en Chile, Santiago, Hachette, 1990.

Womack Jr., J., "Working Power over Production: Labor History, Industrial Work, Economics, Sociology, and Strategic Position", XIV International Economic History Congress, Panel 56: The Economics of Latin American Labor, Helsinki, 2006, Recuperado de:

http://www.helsinki.fi/iehc2006/papers2/Womack.pdf el 1 de abril de 2016.

Womack Jr., J., Posición estratégica y fuerza obrera. Hacia una nueva historia de los movimientos obreros, México, FCE-Fideicomiso Historia de las Américas, Colegio de México, 2007.

\section{Informes gubernamentales}

Acevedo, A., El problema de las faenas marítimas en la zona salitrera. El sistema de redondilla y la nueva reglamentación, Talcahuano, Librería e Imprenta Moderna, 1923.

El problema social-económico del norte, Informe de los señores Carlos A. Ruiz, Cárlos Fernández Peña, Eujenio Frías y Daniel Martner, nombrados por el Supremo Gobierno para estudiar las condiciones de vida en las provincias de Tarapacá y Antofagasta, Ministerio del Interior, Santiago de Chile, 1919.

Informe preparado por el Secretario de la Asociación Salitrera de Propaganda, Iquique, por pedido del Intendente de la Provincia y del Jefe de la Oficina del Trabajo del Ministerio de Industria y Obras Públicas, 1916.

Oyarzún, E., J. E. Concha y J. Philippi, Informe presentado al Supremo Gobierno sobre las huelgas de Iquique en 1916, Santiago de Chile, 1917.

Scott, A., Informes sobre el mejoramiento de los puertos de Mejillones, Antofagasta, Iquique y Arica. Santiago de Chile, Sociedad "Imprenta y Litografía Universo", 1909.

\section{Periódicos y revistas}

Boletín mensual de la Asociación de Productores de Salitre, Valparaíso.

El Despertar de los Trabajadores, Iquique.

El Productor, Iquique.

El Sembrador, Iquique.

El Socialista, Antofagasta.

El Surco, Iquique.

Liga Marítima de Chile. Revista Mensual Ilustrada, Santiago.

\section{Archivos}

Archivo Regional de Tarapacá, Fondo Intendencia de Tarapacá.

Archivo Nacional de la Administración, Oficina del Trabajo. 